\title{
Characterization of anodic biofilm bacterial communities and performance evaluation of a mediator-free microbial fuel cell
}

\author{
Momen Salah Kamel ${ }^{1^{\dagger}}$, Mohamed Hemida Abd-Alla ${ }^{2}$, Usama M. Abdul-Raouf ${ }^{1}$ \\ ${ }^{1}$ Botany and Microbiology Department, Faculty of Science, AL-Azhar University, Assiut, Egypt \\ ${ }^{2}$ Botany and Microbiology Department, Faculty of Science, Assiut University, Assiut, Egypt
}

\begin{abstract}
This study investigated the bioelectrical performance of a single-chamber microbial fuel cell (SCMFC) fueled with acetate as the electron donor and inoculated with municipal solid waste rejected fractions (MSWRFs) as a microbial inoculum. The molecular characterization of the bacterial community structures of the anodic biofilm was conducted based on 16s RNA gene sequencing. The results indicated that the highest open-circuit voltage (OCV) was $797 \mathrm{mV}$ and the system had a maximum power density of $134.5 \mathrm{~mW} / \mathrm{m}^{2}$ at a stable current density of $328 \mathrm{~mA} / \mathrm{m}^{2}$. The microbial fuel cell's (MFC) columbic efficiency (CE) was 55\% at a maximum substrate degradation rate of about $86.6 \%$ based on COD removal efficiency. The molecular analysis of the anodic bacterial isolates indicated that the phylogenetic bacterial mixture was dominated by seven strains with similarity percentage above $99 \%$ for each strain: Enterococcus faecalis, Clostridium butyricum, Bacillus sp., Bacillus subterranous, Enterobacter celoaca, Klebsiella pneumonia, and Escherichia coli. These results suggested that MSWRFs bacterial consortia have a moderate symbiotic structure as indicated by electrons release in parallel with substrate decomposition.
\end{abstract}

Keywords: Bacterial community, Biofilm, Current density, Microbial fuel cell, Power density, 16S rRNA

\section{Introduction}

The modern technologies that help to recover the total energy from municipal solid waste (MSW) are required for the building of a sustainable society. Although chemical and biological approaches to sustainable energy production, such as hydrogen, ethanol, and methane have developed, however many of these approaches have encountered environmental and economic hurdles [1]. The microbial fuel cells (MFCs) represent one of the most promising technologies of recovering electrical energy from household solid waste residues, which are not exploited and dumped in landfills [2]. The MFCs considered one of the Bio Electrochemical Reactors (BERs), which essentially based on the ability of "electrogenic" or "electroactive" bacteria to exchange electrons with the anode through developing effective anodic biofilm [3]. The extracellular electron transmission pathways are possible at both electrodes and different according to the physiology of the bacteria forming biofilm and the terminal electron acceptors [4, 5]. The MFCs as the bioreactors exploit the microbes as biocatalysts for electrical power production from various substrates. Many sub-

This is an Open Access article distributed under the terms of the Creative Commons Attribution Non-Commercial License (http://creativecommons.org/licenses/by-nc/3.0/) which permits unrestricted non-commercial use, distribution, and reproduction in any medium, provided the original work is properly cited.

Copyright (C) 2020 Korean Society of Environmental Engineers strates act as the MFC fuel for generating electricity, including wastewater, agriculture wastes, and food industrial wastes [6, 7].

Two particular methods of transferring the generated electrons to the MFCs anode, the first one is the mediated electron transmission mechanism (MET), which an external mediator required to start the interactions of the electrode biofilm [8, 9]. Conversely, the second method is the direct electron transmission (DET) mode. In DET mode, there is a physical adhesion between the microorganisms and the surface of the electrode anode leading to the direct transmitting of electrons from the microorganism's cell wall among nanowires to the electrodes [10-12]. The electrogenic microorganisms are considered the key feature of MFCs operation due to their ability to release electrons during the degradation of organic substrates [13]. The stimulation of electrogenic bacteria requires a carbon source and acetate is one of the most important and widely used sources, In addition to acetate is commonly used as a chemical reactivator for microbes at room temperature [14]. Acetate is the final product for complicated carbon sources of several metabolic pathways. The MFCs last researches indicated that there is a great potential in generating electricity from MSW depending
Received October 8, 2019 Accepted November 18, 2019
${ }^{\dagger}$ Corresponding author
Email: m.s.kamel@outlook.com, from_Assiut@hotmail.com
Tel: +100698324520

ORCID: 0000-0003-4503-7205 
on their chemical content, which can act as an excellent fuel to encourage the bioelectricity generation [15, 16]. The most significant global issues in MSW management strategies are the search for eco secure techniques of its final disposal. Ordinary, MSW management in different countries based on the MSW collecting, raw materials recovering, materials recycling, manure production, and producing electric power through incineration [17]. The final disposal carried out through developed landfills where methane gas extracted and used as biofuel through a gas distribution network. There are several Environmental impacts when MSW landfills such as odor production, self-heating, self-combusting, biogas production, leachate and pathogen growth [18]. In general, during the MSW treatment process, the uneconomical residual portions are dumped in landfills. However, this residual portion, which commonly referred to the rejected fractions can be environmentally and economically valuable by being handling mechanically and transformed into refuse-derived fuel (RDF) [19]. The RDF used as an alternative fuel source in cement kilns because it has a high calorific value, but this method is accompanied by $\mathrm{SO} 2, \mathrm{CO} 2$, and NOx, emissions that cause negative environmental impacts [20]. As mentioned previously the electrogenic microbial content is the main driver that affects the MFCs performance, therefore the anodic microbial communities should be defined precisely to investigate the temporal dynamics of the anodic biofilm. 16S rRNA gene sequencing is the most famous technique used to characterize the bacterial strains involved in bioelectricity production [21]. These molecular techniques include clone library analysis and Denaturing Gradient Gel Electrophoresis (DGGE), which used for analyzing microbial community structures, diversity, and attributes [22]. The advantages of DGGE over other profiling techniques are that it is rapid, affordable, and valuable as a first-line bacterial community's examination [23]. These techniques were used to know how the dynamics of the microbial community are linked to the operation of the MFCs [24].

The present article was aimed at characterizing the anodic bacterial community structure of the single chamber microbial fuel cell inoculated with MSWRFs as a bacterial source. Also, this study was extended to assessing MFC performance.

\section{Experimental Methods}

\subsection{MFC Assembly and Operation}

A mediator-less SCMFC was used as a bioreactor for power generation from acetate as a carbon source (MFC fuel). The MFC was inoculated with the MSWRFs as the initial bacterial inoculum. Fig. 1 shows the diagrammatic design of the fabricated MFC. The cell was fabricated from Perspex material (Homemade, Assiut University, Assiut, Egypt) with a total inner volume of $50 \mathrm{ml}$. The design of the reactor allows the atmospheric air to come into contact the outside cathode surface through small bores and maintaining the anode zone within anaerobic environment. The MFC electrodes have the same size, a Microporous wet proofed layer (MWPL) carbon cloth (www.fuel cell store.com) was installed in the cathodic zone as a cathode, while carbon cloth (Type A, E-TEK) as the Anode was installed in the anodic area. The distance separating the electrodes was $6 \mathrm{~cm}$ with no membrane applied and the surface-active area of both electrodes was $25 \mathrm{~cm}^{2}$. All tests were completed at room temperature of about $30^{\circ} \mathrm{C}$, which considered the optimum temperature for the bacterial activity [25]. The MFC performance analysis was conducted according to the mathematical calculation of the system's bioelectricity output.

\subsection{Bacterial Growth Stimulation}

The fabricated MFC was configured, sterilized, and inoculated with the mixed bacterial culture of the MSWRFs sample. The MSWRFs samples were obtained from the Manqabad Compost and Recovery Facility (Assiut, Egypt). The MSWRFs sample was processed through screening and filtration stages to remove un-dissolved materials using distilled water. The MFC was fueled with the acetate synthetic medium as the initial carbon source. The growth medium

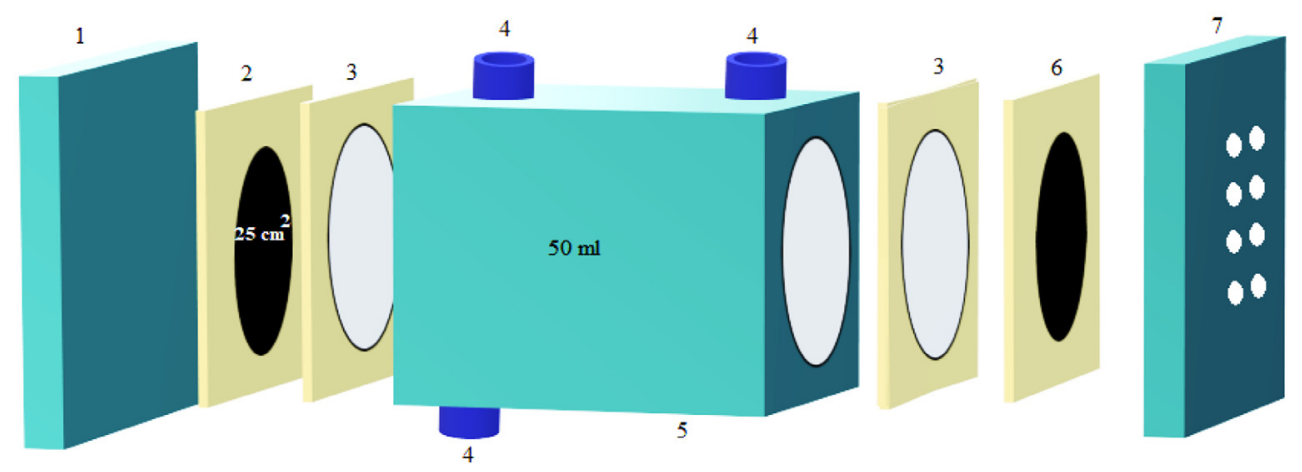

1: Plastic Housing

2: Carbon Cloth Anode

3: Butyl rubber gaskets

4: Inlet and outlet ports

5: Reactor container

6: Carbon Cloth (MWPL) Cathode

7 Plastic Housing with oxygen exposure holes

Fig. 1. The diagrammatic design of fabricated MFC. 
was prepared as mentioned in Dena et al [26]. Moreover, The MFC output data have been recorded continuously during three consecutive cycles of fed-batch operational mode.

\subsection{MFC Startup and Operating Procedures}

The MFC was operated under both open circuit voltage mode (OCV) and closed-circuit voltage mode (CCV) using $550 \Omega$ as external resistance (the corresponding resistance of the highest current density and power density obtained from the plotted polarization curve as mentioned in the result section). For further investigation, the MFC was subjected to several external resistances (200, 550, 750, and $1000 \Omega$ ) through three consecutive operational cycles. Among the both operational modes, the Cell Potential between MFC electrodes was recorded every one minute among three consecutive cycles with the advanced multimeter (FLUKE 289 - TRUE RMS). After the voltage reading was stapled at the highest OCV value, the polarization curve was plotted by applying various external resistances (Rext) from 100 to $10000 \Omega$. The chemical oxygen demands (COD chromate) were evaluated according to the standard methods [8] at the end of the operational cycles [9]. The catalytic $\mathrm{pH}$ was fixed at 7.0 according to the standard methods [10] and the $\mathrm{pH}$ value changes was measured using a $\mathrm{pH}$ meter (DP-880, Dong-Woo, Korea) during the CCV operational cycles .

\subsection{Analysis and Calculation}

The MFC potential was recorded every $1 \mathrm{~min}$ with a fluke multimeter (FLUKE 289 - TRUE RMS). The current and the harvested power were calculated from the following formula [11, 12].

$$
I=\frac{V_{M F C}}{R_{\text {ext }}}
$$

Where $\mathrm{V}_{M F C}$ is the measured voltage, $\mathrm{R}_{\text {ext }}$ is the external load applied. Current density $\left(\mathrm{mA} / \mathrm{m}^{2}\right)$ was calculated from the followed equation $[13,14]$ :

$$
\text { C. D }=\frac{I}{A}
$$

Where I is the current per $\mathrm{mA}$ and $\mathrm{A}$ is the projected area of the anode $\left(\mathrm{m}^{2}\right)$. The Power density (PD, $\left.\mathrm{mW} / \mathrm{m}^{2}\right)$ was calculated from the followed equation [15]:

$$
P . D=V_{M F C} x C . D
$$

The Columbic efficiency (CE), describes the efficiency of the MFC in facilitating the electrochemical reactions for charge (electrons) transmission, i.e. the Current represented in the recovered fraction electrons versus the complete of oxidation of the substrate. The CE was calculated by the followed equations [15-18]:

$$
\begin{gathered}
C E=\frac{C_{P}}{C_{T}} \times 100 \% \\
C_{T}=\frac{F n \Delta \mathrm{c} V}{\mathrm{M}}
\end{gathered}
$$

Where the $\mathrm{C}_{\mathrm{P}}$ is actual current production collected by the anode during one batch cycle was integrated as $\left(\mathrm{C}_{\mathrm{P}}=x t\right)$ and the $\mathrm{C}_{\mathrm{T}}$ is the theoretically available amount of produced coulombs depending on the COD removed in the MFC from the fully oxidation of substrate organic content into $\mathrm{CO}_{2}$ and water. It was estimated as in formula no.5, where $\mathrm{F}=$ faraday's constant $(96485 \mathrm{C} / \mathrm{mol})$, $\mathrm{n}=$ no. of electrons per mole of substrate ( $=4$ electrons), $\Delta \mathrm{c}$ is the daily COD removed, $\mathrm{V}$ is the inner reactor volume per liter, $\mathrm{M}=$ molecular weight of $\mathrm{O}_{2}$ (= $32 \mathrm{~g} /$ mole).

COD removal efficiency calculated as the following equation $[19,20]$ :

$$
C O D \text { removal efficiency }=\frac{C O D_{\text {inlet }}-C O D_{\text {outlet }}}{C O D_{\text {inlet }}} \times 100
$$

$\mathrm{COD}_{\text {inlet }}$ represents the initial COD concentration $(\mathrm{mg} / \mathrm{l})$ in the feed and $\mathrm{COD}_{\text {outlet }}$ denotes COD concentration $(\mathrm{mg} / \mathrm{l})$ in the reactor outlet.

\subsection{Bacterial Community Analyses}

All experimental analyses were conducted under aseptic conditions, $1.0 \mathrm{~mL}$ from anolytic bacterial mixed culture was sampled from the anode zone and the bacterial cells were isolated through centrifugation and filtration technique for $5 \mathrm{~min}$ and kept at $4^{\circ} \mathrm{C}$ according to the methods described previously in Khater et al. [21]. The extracted Bacterial isolates were screened on a nutrient agar medium (NA) plates by the conventional pour plate technique. The NA plates were incubated at $37^{\circ} \mathrm{C} / 24 \mathrm{~h}-48 \mathrm{~h}$. The characterized colonies were obtained for further purification profiling analysis. The isolated bacterial strains were subjected to the systematic identifying lines such as morphological characterizing, gram staining, and biochemical tests [22].

\subsection{Molecular and Phylogenetic Analysis}

The bacterial isolates were sent to SolGent laboratories (Solgent Company, Daejeon city, South Korea) for advanced molecular analysis of $16 \mathrm{~S}$ rRNA gene sequences. Moreover, the Bacterial isolates were subjected to SolGent lab identification protocols initially SolGent purification bead was used to extract and isolate bacterial DNA. Before 16S rRNA gene sequencing, the ribosomal rRNA genes were amplified using the polymerase chain reaction (PCR) technique in which Two universal primers were used for amplification:

Forward primer 27f (5'-AGAGTTTGATCCTGGCTCAG-3') and reverse primer 492r (5'-TACG GYTACCTTGTTACGACTT-3'). The PCR products were purified and sequenced using PCR purifying kits (Cosmo Genetech, Republic of Korea). Consequently, the purified PCR products were reconfirmed (using a size marker) by electrophoresis on $1 \%$ agarose gel. Then these clusters were sequenced and eluted with the integration of dideoxy nucleotides (dd NTPs) in the mixture of reactions. Further analysis conducted with BLAST(Basic Local Alignment Search Tool) of the website of the national biotechnology information center. Phylogenetic analysis of sequences was conducted using software version 5.05 MegAlign (DNA Star). The partial 16s rRNA sequences of the selected bacterial strains have been aligned with BLAST which is a web-based program able to align unknown sequences to thousands of dissimilar and 
similar sequences in a gigantic Database and show the list of top matches Instantly. BLAST platform performs its alignment by matching up each position of search sequence to each position of the sequences in the database [23]. BLAST provides an accurate positive score for matching nucleotides; also, it demonstrates the gaps when performing the alignment. The inserted gaps have a negative effect on the degree of the alignment, but in the case of the alignment of a sufficient number of nucleotides as a result of the gap, it is to overcome this negative impact and the gap is accepted in the alignment [24]. These results then employed for constructing the phylogenetic tree through determining the alignment score, in "bits" which is converted to the statistical Evalue, which estimates the degree of similarity of sequences in the GenBank database [25].

\section{Results and Discussion}

\subsection{Microbial Fuel Cell Performance}

The MFC was operated in a fed-batch mode to induce the dynamic growth of electrogenic bacteria to reach the highest performance of the bioreactor. Fig. 2 illustrated the tested MFC efficiency over three consecutive cycles under the fed-batch operational process at OCV mode. The results observed that the higher OCV output was contributed to decreasing cell life, so the generated voltage of the MFC expected to reduce overtime, this observation was consistent with the previous literature [26, 27]. The results indicated a sequential increase in voltage values, which was reached 748 $\mathrm{mV}$ after 6 days of the first operational cycle. The voltage was decreased sequentially to less than $100 \mathrm{mV}$ at the end of the $10^{\text {th }}$ day of operation due to the microbial activity and an increase in substrate consumption. Based on the fed-batch operational mode the reactor was supplied with acetate substrate and MSWRFs inoculum for the second cycle. As a result, the voltage increased again and $756 \mathrm{mV}$ was the highest voltage obtained at the end of the $15^{\text {th }}$ day of the operation before the decline phase. The voltage reached to maximum steady value at $797 \mathrm{mV}$ within 24 days under OCV mode in the third operational cycle (Fig. 2). The MFC was operated in OCV mode for three consecutive rounds and at the end of each cycle, both acetate solution and a new batch of MSWRFs inoculum were added to reactivate the anodic electrode with active microorganisms and enhance the anodic biofilm development [28].

The MFC was inoculated with mixed bacterial culture using MSWRFs inoculum, which proved through the study, their ability to utilize the synthetic substrate containing acetate as a carbon source. The current study results showed a dramatic increase in the bioreactor voltage after fueled with acetate substrate and inoculum. Notwithstanding the voltage values were not recorded at the start of bioreactor operation on OCV mode due to no biofilm on the anode has been formed. When the bacterial consumption of the substrate was started the voltage values were increased significantly with time. After that, the cell potential was dropped gradually by the end of the first operational cycle. The current study results revealed that the ability of bacterial content in MSWRFs inoculum to catalyzing bioelectricity generation from acetate synthetic

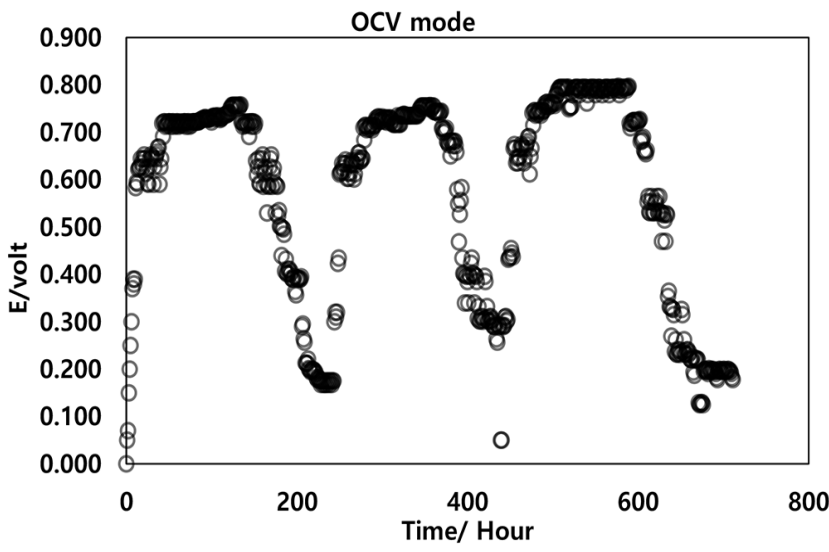

Fig. 2. Potential versus time curve among three consecutive operational cycles at OCV mode.

medium using the MFCs systems. In a previous study by Dena et al. [29], they used the aerobic mixed bacterial culture from wastewater sludge as a microbial catalyst and Acetate synthetic substrate in the single-chamber mediator less MFC, the reactor maximum voltage output reached $791 \mathrm{mV}$ using acetate carbon source within 19 days. Once the addition process of the inoculum and substrate have replicated among three consecutive series, The MFC operations are stable and observable in addition to the anodic surface developing anodic biofilm for electrons, protons, $\mathrm{CO}_{2}$ production, and closely tied to the microorganism [30-32].

The MFC electrical performance was evaluated using polarization analysis. The polarization and power curves were plotted after the reactor OCV potential reached the maximum steady phase by adding a range of external resistances (100 -10000 $\Omega$ ). The polarization curve of the operated MFC showed that the highest harvested MFC power was obtained at $550 \Omega$ [33]. Accordingly, the MFC was operated in closed-circuit voltage mode (CCV) through applying $550 \Omega$ as external resistance. The reactor was worked for three consecutive cycles in the fed-batch mechanism in the same manner as the previous OCV operation. The highest CCV voltage value in the third cycle of operation was $318.8 \mathrm{mV}$ (Fig. 3b). During all three operational cycles in both OCV and CCV modes, the values of the recorded voltage results maybe, attributed to the formation of the biofilm on the surface of the anode, furthermore the capacity for bacterial content to produce and transfer the electrons to the anode surface without chemical mediators.

Fig.3 shows the relationship between the MFC harvested power in the form of power density and current density among several external resistances versus the time. According to Ohm's law, potential and resistance have a direct relationship. In other words, as resistance increases, voltage increases, and current decreases. From the illustrated power charts (fig.3a:3d), it can be concluded that there is an inverse relationship between current density and resistance. As expected, higher resistance leads to lower the generated current. The current and power densities were peaked at $550 \Omega$ with values reached $330 \mathrm{~mA} / \mathrm{m}^{2}$ and $135 \mathrm{~mW} / \mathrm{m}^{2}$ respectively. When the cell was worked under $750 \Omega$, the highest current density was $280 \mathrm{~mA} / \mathrm{m}^{2}$ while the power density was $128 \mathrm{~mW} / \mathrm{m}^{2}$. When the MFC was operated at $1000 \Omega$ the highest recorded values of 

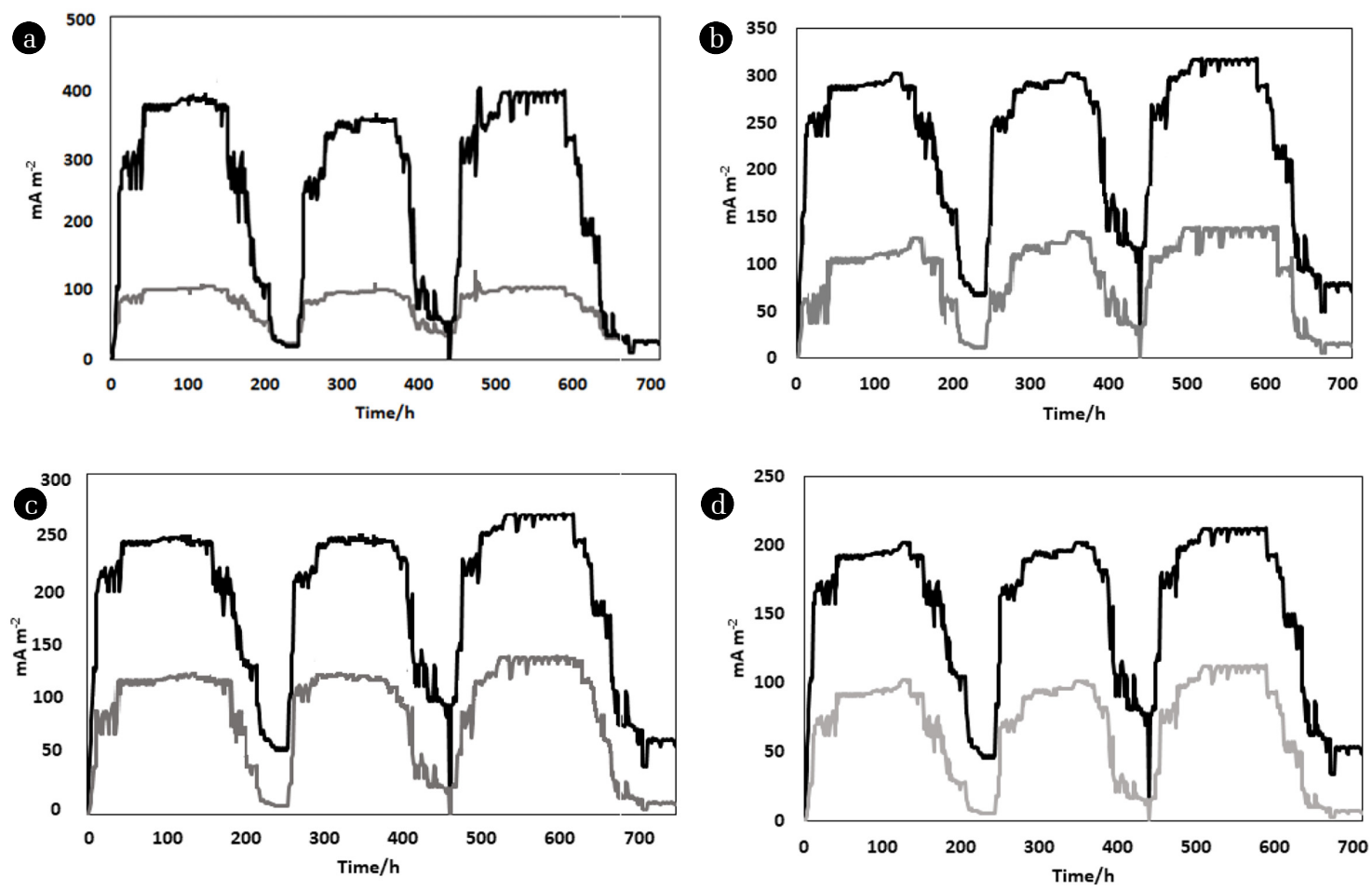

$$
\text { -Current Density } \quad \text { - Power Density }
$$

Fig. 3. (a) The MFC Performances at $200 \Omega$ density and Power density vs. time. (b) The MFC Performances at $550 \Omega$ density and Power density vs. time. (c) The MFC Performances at $750 \Omega$ density and Power density vs. time. (d) The MFC Performances at $1000 \Omega$ density and Power density vs. time.

current and power densities were $220 \mathrm{~mA} / \mathrm{m}^{2}$ and $119 \mathrm{~mW} / \mathrm{m}^{2}$ respectively. As expected, the current density and power density readings were changed when the reactor operated at $200 \Omega$ with maximum records were $410 \mathrm{~mA} / \mathrm{m}^{2}$ and $105 \mathrm{~mW} / \mathrm{m}^{2}$ respectively. The results demonstrated that the MFC performance was enhanced with the application of the optimal external resistance, these observations have found in accordance with the previous literature [34]. The $\mathrm{pH}$ value has a strong effect on MFC microbial activity which is reflected in the overall MFC performance [35]. Changes in the $\mathrm{pH}$ value also affect the metabolism and absorption of nutrients through influencing the solubility of nutrients, thus affecting the growth rate of microorganisms. Because any microorganisms should live in optimal $\mathrm{pH}$ value, microbial growth can be inhibited when the $\mathrm{pH}$ environment is below or above the appropriate $\mathrm{pH}$ value [36]. Fig. 4a illustrates the changes in $\mathrm{pH}$ value when the cell was operated under the influence of several different external loads. From the graph, it can be revealed that the interaction effect between $\mathrm{pH}$ and resistance was remarkable, and then the relationship between the resistance and $\mathrm{pH}$ value has a direct effect on MFC performance. When the cell was reached the highest performance at 550 as mentioned above the $\mathrm{pH}$ value was 7.5 . These findings were matched with the previous literature [36, 37], they revealed that the effect of $\mathrm{pH}$ on power density generation was highly depended on the level of the external resistance.

\subsection{Polarization Characteristics}

The study of Polarization characteristics provides an important tool for examining and classifying MFCs through analysis of the changes in MFCs potential from balance condition owing to a streaming current. These characteristics were determined when the voltage reached a stable state in OCV operational mode; various external resistances have been added. Fig. $4 \mathrm{~b}$ shows the polarization graph as a factor of current and power density against the potential for acetate at various resistances. The maximum reported MFC current density, power density, and current were $328 \mathrm{~mA} / \mathrm{m}^{2}, 134.4 \mathrm{~mW} / \mathrm{m}^{2}$, and $0.82 \mathrm{~mA}$ respectively. Internal resistance was calculated by determining the slope of the plotted voltage versus current as mentioned elsewhere [38] and it was approximately200 $\Omega$ that was within the same scope of other researchers [39]. Dina et al. [9], stated that the maximum current density generated from wastewater sludge as bacterial inoculum and acetate as substrate was of 235.11 $\mathrm{mA} / \mathrm{m}^{2}$, with a Furthermore, internal resistance was $59 \Omega$. Cheng et al. [40] reported that the Maximum current densities, power densities and columbic efficiencies where no mediators added to representative freshwater mixed culture microbial fuel cells were $1.05 \mathrm{~mA}, 276.6 \mathrm{~mW} / \mathrm{m}^{2}$, and $32 \%$, respectively. The polarization curve indicated that the power was generated by the system considers the principal objective of fabricated MFC. The polarization curve analysis demonstrated the relation between carbon source as critical for the microbial activity and the electrical current generation. 

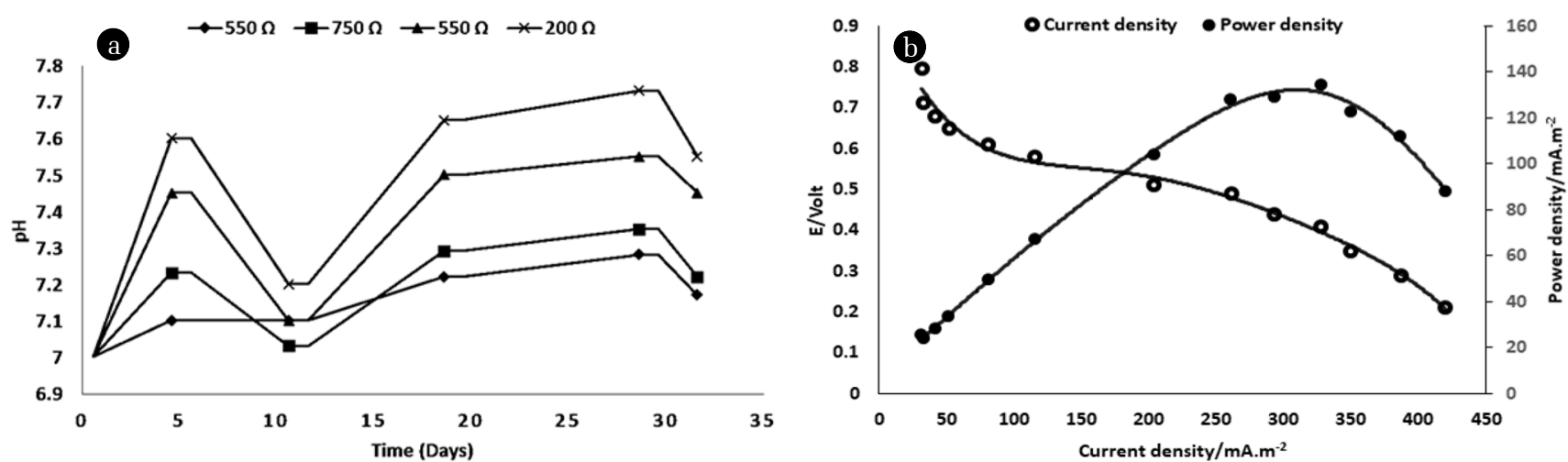

Fig. 4. (a) The changes on $\mathrm{pH}$ values against the time under several external resistances. (b) Current density-voltage and current density-power relationships for the operated MFC.

\subsection{Substrate Degradation and COD Removal}

The COD removal efficiency was evaluated for various samples that collected daily from the MFC and the findings cleared that the COD removal efficiency was increased over time of MFC operation. Fig. 5 clarifies the degradation of acetate (COD values) versus time. The initial COD of acetate was $1640 \mathrm{mg} \cdot \mathrm{L}^{-1}$ at resistance

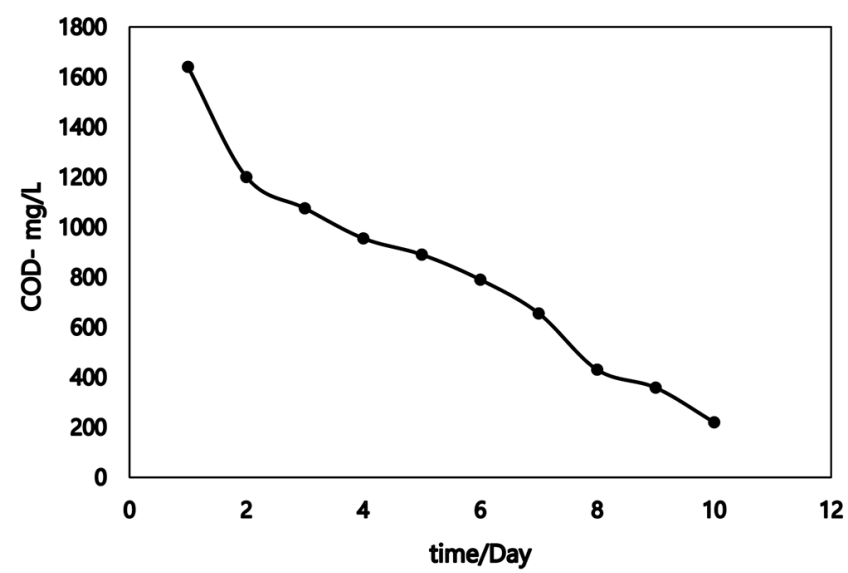

Fig. 5. The MFC COD removal efficiency among full operational cycle.
$550 \Omega$. The graph cleared that there is a correlation between the substrate consumption and the bioelectricity production, where the voltage value on the CCV MFC operational fifth day was $320 \mathrm{mV}$ and the COD efficiency ratio was about $70 \%$, while the maximum removal efficiency was $86.6 \%$ by the end of the cycle duty. These results are in line with previously recorded results Dina et al [35]. They revealed that the percentage of COD removal of acetate fed MFCS reached $96 \%$ at the end of the MFC operation time. The difference in values of COD removal efficiency could be explained by different microbial sources (inoculum), microbial community structures, MFC configuration, electrodes type, and microbial activity. The findings of the current study indicated that the inoculated mixed bacterial culture capable to produce bioelectricity in the presence of a substrate rich in nutritional sources.

The coulombic efficiency (CE) referred to the total charge proportion transmitted into the anode over the highest extractible charge after full oxidation of the substrate translated to electricity [41]. The acetate coulombic efficiency is $55 \%$; this result verified the inverse relationship between coulombic efficiencies and substrate concentration. The CE ratio recorded in this study falls within the range of Fan et al. [42] measurements which were $35 \%$ and $71 \%$.
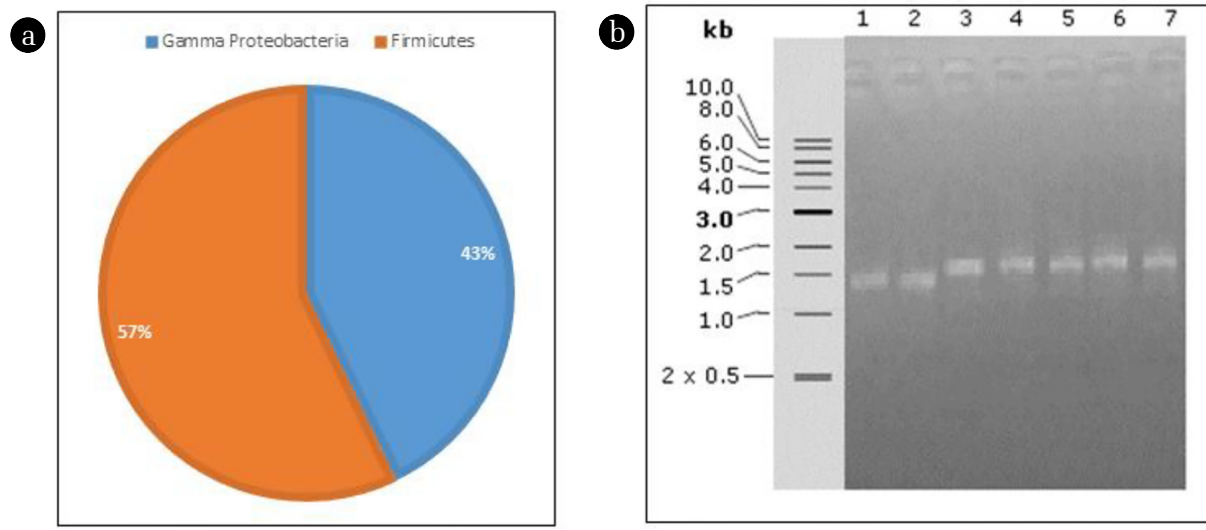
1: Clostridium butyricum MSK 1. $1474 \mathrm{bp}$
2: Escherichia coli MSK 1. $1450 \mathrm{bp}$
3: Bacillus sp MSK 1. 1548 bp
4: Enterococcus faecalis MSK 1. $1517 \mathrm{bp}$
5: Bacillus subterraneus MSK 1. $1539 \mathrm{bp}$
6: Klebsiella pneumonia MSK 1. 1492 bp
7: Enterobacter cloacae MSK 1. $1529 \mathrm{bp}$

Fig. 6. (a) The distributing percentage off anodic biofilm bacterial communities. (b) Gel electrophoresis (DGGE) of PCR-amplified 16S rRNA genes for selected bacterial isolates. 
Table 1. The Bacteria Isolates Identity Based On $16 \mathrm{~S}$ rRNA Gene Sequences

\begin{tabular}{|c|c|c|c|c|}
\hline band & Bacterial strain & Phylum & Accession number & Similarity (\%) \\
\hline 1 & Clostridium butyricum MSK strain & Firmicutes & MK571204.1 & $>99 \%$ \\
\hline 2 & Escherichia coli MSK strsin & Gammaproteobacteria & MK572635.1 & $>99 \%$ \\
\hline 3 & Bacillus MSK strain & Firmicutes & MK571602.1 & $>99 \%$ \\
\hline 4 & Enterococcus faecalis MSK strain & Firmicutes & MK571202.1 & $>99 \%$ \\
\hline 5 & Bacillus subterraneus MSK strain & Firmicutes & MK571199.1 & $>99 \%$ \\
\hline 3 & Klebsiella pneumonia MSK strain & Gammaproteobacteria & MK571198.1 & $>99 \%$ \\
\hline 4 & Enterobacter cloaca MSK strain & Gammaproteobacteria & MK571201.1 & $>99 \%$ \\
\hline
\end{tabular}

\subsection{Molecular Analysis of Biofilm Formed on the Electrodes}

The results demonstrated that the anodic biofilm and the anolyte were enriched with a phylogenetic bacterial variety with no single dominant bacterial species. The anode bacterial diversity was dominated by Proteobacteria phylum (57\%), accompanied by phyla Firmicutes (43\%) (Fig. 6a) depending on DGGE pattern intensities and 16s rRNA gene sequences with seven bacterial strains: Clostridium butyricum, Escherichia coli, Bacillus sp., Enterococcus faecalis, Bacillus subterraneus, Klebsiella pneumonia, and Enterobacter cloaca (Table 1). The alignment identity was more than $99 \%$ for each strain. Most of these species were facultative anaerobes; this may be matched with the fact that the species capable of transporting electrons are limited to the biofilm strains [43]. Fig. $6 \mathrm{~b}$ illustrates the sequencing results of the bands of the PCR- DGGE analysis profiles of the 16S rRNA gene fragments which

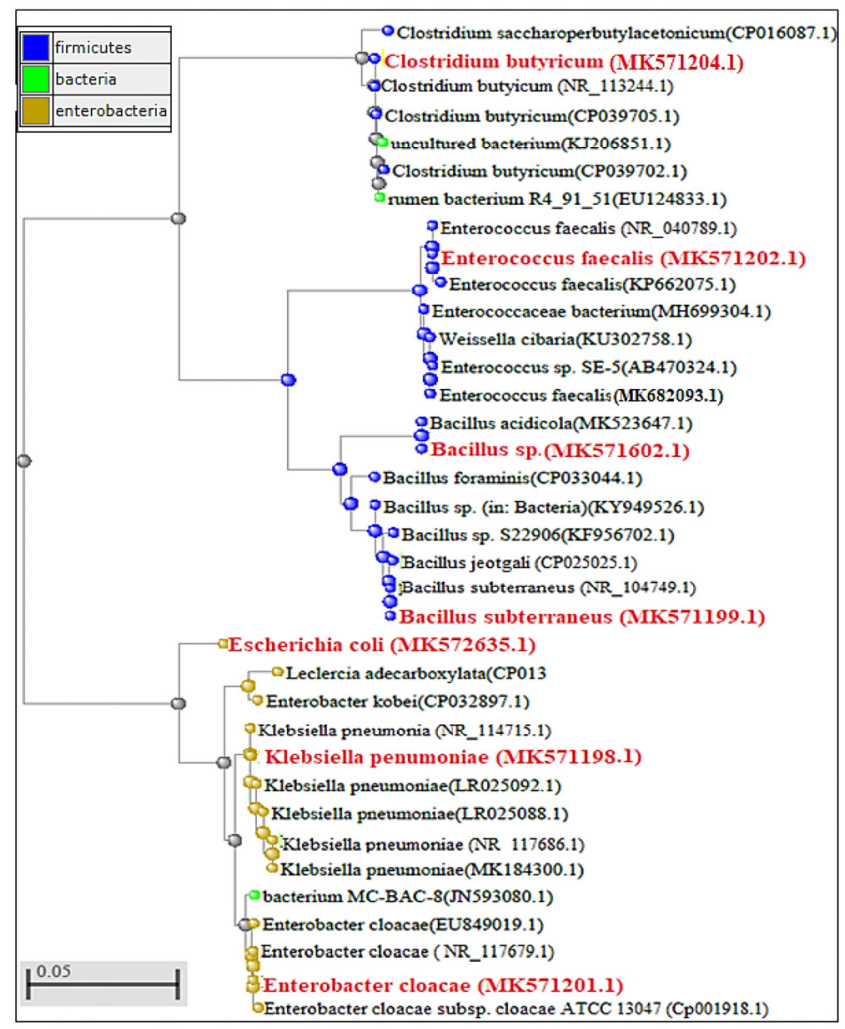

Fig. 7. Phylogenetic based on partial $16 \mathrm{~S}$ rRNA gene sequences of the anodic bifilm bacterial isolates. amplified from the extracted bacterial DNA of the biofilm and the anodic zone solution at the end of the fed-batch operation. Each band on the DGGE profile specifies a bacterial species in the microbial aggregation and the band discoloration displays the relative microbial population. Banding model and band intensity Changes of the biofilm bacterial content were observed through the detectable bands in the DGGE patterns, all bands are illustrated with very high intensity. One study of single-chamber MFCs demonstrated that the Proteobacteria and Firmicutes phyla could be enriched in acetate-fueled MFCs and dominates the anodic electrons transmission [9]. The phylogenetic tree has been constructed based on bacterial partial 16S rRNA gene sequences of MFC anodic biofilm (Fig.7). The phylogenetic profile detected a bacterial community in the anodic biofilm confined in Gamma Proteobacteria of the phylum Proteobacteria and Firmicutes phylum.

\section{Conclusions}

The current study was investigated the bioelectrical performance of the mediator-less single-chamber MFC inoculated with MSWRFs as a microbial source and fueled with acetate as electron donor. The MFC performance was observed after three consecutive operational cycles during 34 days of fed-batch mode. The findings supported the hypothesis that the bacterial heterogeneity of the anode surface is the main responsible factor for MFC efficiency. According to the monitoring of COD removal efficiency, the study was indicated that the acetate was oxidized completely which translated into a direct transmission of the electrons to the anode. The COD removal efficiency of acetate was $86.6 \%$ with a coulombic efficiency of about 55\%. The maximum recorded OCV voltage was $797 \mathrm{mV}$. The bioreactor was successfully revealed a maximum power density of $134.5 \mathrm{~mW} / \mathrm{m}^{2}$ at a stable current density of $328 \mathrm{~mA} / \mathrm{m}^{2}$. On the basis of 16s rRNA gene sequences analyses, the anodic bacterial diversity was dominated by Proteobacteria phylum (57\%), accompanied by phyla Firmicutes (43\%) depending on DGGE pattern intensities and 16S rRNA sequences with seven bacterial strains: Clostridium butyricum, Escherichia coli, Bacillus sp., Enterococcus faecalis, Bacillus subterraneus, Klebsiella pneumonia, and Enterobacter cloaca. All identified strains were registered in the GenBank platform and received accession numbers. The obtained results were compared with the previous literature and the current study demonstrated the potential of the bacterial content of MSWRFs to produce electricity using MFCs. 


\section{Acknowledgment}

This work supported by Al Azhar University, Assiut, Egypt (www.Azhar.edu.eg). The authors would like to thank Prof. Dr. Kamel El-Khatib (Chemical Engineering at National Research Center) for critical reading, helpful comments, constructive suggestions, and careful corrections for further improvement of this manuscript.

\section{Author Contributions}

M.S.K. (PhD student) performed experiments, analysed data and co-wrote the paper. M.H.A. (Professor) designed the experiments, co-wrote the paper and supervised the research. U.M.A. (Professor) supervised the research.

\section{References}

1. Datar R, Huang J, Maness P-C, Mohagheghi A, Czernik S, Chornet E. Hydrogen production from the fermentation of corn stover biomass pretreated with a steam-explosion process. Int. J. Hydrog. Energ. 2007;32:932-939.

2. Logan BE, Regan JM. Electricity-producing bacterial communities in microbial fuel cells. Trends Microbiol. 2006;14:512-518.

3. Sharma M, Bajracharya S, Gildemyn S, et al. A critical revisit of the key parameters used to describe microbial electrochemical systems. Electrochimi. Acta. 2014;140:191-208.

4. Lovley DR. Extracellular electron transfer: wires, capacitors, iron lungs, and more. Geobiology 2008;6:225-231.

5. Pant D, Singh A, Van Bogaert G, et al. Bioelectrochemical systems (BES) for sustainable energy production and product recovery from organic wastes and industrial wastewaters. Rsc Adv. 2012;2:1248-1263.

6. Kumar P, Chandrasekhar K, Kumari A, Sathiyamoorthi E, Kim B. Electro-fermentation in aid of bioenergy and biopolymers. Energies 2018;11:343-20.

7. Peng L, Dai H, Wu Y, Peng Y, Lu X. A comprehensive review of the available media and approaches for phosphorus recovery from wastewater. Water Air Soil Pollut. 2018;229:115.

8. American Public Health A, Eaton AD, American Water Works A and Water Environment F. Standard methods for the examination of water and wastewater. Washington, D.C.: APHA-AWWAWEF; 2005.

9. Khater DZ, El-Khatib KM, Hassan HM. Microbial diversity structure in acetate single chamber microbial fuel cell for electricity generation. J. Genet Eng. Biotechnol. 2017;15:127-37.

10. Association APH, Association AWW, Federation WPC and Federation WE. Standard methods for the examination of water and wastewater. American Public Health Association; 1915.

11. Rahimnejad M, Ghoreyshi AA, Najafpour G, Jafary T. Power generation from organic substrate in batch and continuous flow microbial fuel cell operations. Appl.Energ. 2011;88:3999-4004.

12. Rabaey K, Lissens G, Siciliano SD, Verstraete W. A microbial fuel cell capable of converting glucose to electricity at high rate and efficiency. Biotechnol. Lett. 2003;25:1531-1535.

13. Min B, Cheng S, Logan BE. Electricity generation using membrane and salt bridge microbial fuel cells. Water Res. 2005;39: 1575-1586.

14. Liu H, Logan BE. Electricity generation using an air-cathode single chamber microbial fuel cell in the presence and absence of a proton exchange membrane. Environ. Sci. Technol. 2004;38:4040-4046.

15. Catal T, Li K, Bermek H, Liu H. Electricity production from twelve monosaccharides using microbial fuel cells. J. Power Sources. 2008;175:196-200.

16. Heilmann J, Logan BE. Production of electricity from proteins using a microbial fuel cell. Water Environ. Res. 2006;78:531-537.

17. Ringeisen BR, Ray R, Little B. A miniature microbial fuel cell operating with an aerobic anode chamber. J. Power Sources. 2007;165:591-597.

18. Ieropoulos IA, Greenman J, Melhuish C, Hart J. Comparative study of three types of microbial fuel cell. Enzyme Microb. Technol. 2005;37:238-245.

19. Freguia S, Rabaey K, Yuan Z, Keller J. Non-catalyzed cathodic oxygen reduction at graphite granules in microbial fuel cells. Electrochimica Acta. 2007;53:598-603.

20. Rodrigo M, Canizares P, Lobato J, Paz R, Sáez C, Linares J. Production of electricity from the treatment of urban waste water using a microbial fuel cell. J. Power Sources. 2007;169: 198-204.

21. Khater D, Hazaa M, El-khatib K, Hassan RY. Activated sludge-based microbial fuel cell for bio-electricity generation. J. Basic Environ. Sci. 2015;2:63-73.

22. Sanders ER. Aseptic laboratory techniques: plating methods. J Vis Exp. 2012;e3064-e.

23. Robinson CJ, Bohannan BJ, Young VB. From structure to function: The ecology of host-associated microbial communities. Microbiol Mol. Biol. Rev. 2010;74:453-476.

24. Bayat A, Gaëta B, Ignjatovic A, Parameswaran S. Pairwise alignment of nucleotide sequences using maximal exact matches. BMC Bioinformatics. 2019;20:261-261.

25. McGinnis S, Madden TL. Blast: At the core of a powerful and diverse set of sequence analysis tools. Nucleic Acids Res. 2004;32:W20-W25.

26. Leite Lobo F. Energy Management of Microbial Fuel Cells for High Efficiency Wastewater Treatment and Electricity Generation [dissertation]. Colorado: Univ. Colorado at Boulder; 2018.

27. Roy S, Pandit S. Microbial Electrochemical System: Principles and Application. Microbial Electrochemical Technology. Elsevier; 2019.p.19-48.

28. Barton SC, Minteer S, De Long H, Kano K. Biological Fuel Cells 3. The Electrochemical Society; 2008.

29. Khater DZ, El-Khatib K, Hassan HM. Microbial diversity structure in acetate single chamber microbial fuel cell for electricity generation. J. Genet Eng. Biotechnol. 2017;15:127-37.

30. Franks A, Malvankar N, Nevin K. Bacterial biofilms: The powerhouse of a microbial fuel cell. Biofuels 2010;1:589-604.

31. Sasaki D, Sasaki K, Tsuge Y, Kondo A. Less biomass and intracellular glutamate in anodic biofilms lead to efficient electricity generation by microbial fuel cells. Biotechnol. Biofuels. 2019;12:72. 
32. Santoro C, Babanova S, Artyushkova K, et al. Influence of anode surface chemistry on microbial fuel cell operation. Bioelectrochemistry 2015;106:141-149.

33. Song Y, Boghani H, Kim H, et al. Electricity production by the application of a low voltage DC-DC boost converter to a continuously operating flat-plate microbial fuel cell. Energies 2017;10:596

34. Mansoorian HJ, Mahvi AH, Jafari AJ, Khanjani N. Evaluation of dairy industry wastewater treatment and simultaneous bioelectricity generation in a catalyst-less and mediator-less membrane microbial fuel cell. J. Saudi Chem. Soc. 2016;20:88-100.

35. Vilajeliu-Pons A, Puig S, Rovira A, et al. Effect of Hydrodynamics on MFC Microbial Community. In: 2nd European International Society for Microbial Electrochemistry and Technology Meeting;3-5 September 2014; Alcalá de Henares, Spain.

36. Rago L, Baeza JA and Guisasola A. Increased performance of hydrogen production in microbial electrolysis cells under alkaline conditions. Bioelectrochemistry 2016;109:57-62.

37. Córdova-Bautista Y, Paraguay-Delgado F, Perez Hernandez B, Perez Hernandez G, Martinez Pereyra G, Ramírez me. Influence of external resistance and anodic $\mathrm{pH}$ on power density in microbial fuel cell operated with B. subtilis BSC-2 strain. Appl. Ecol.
Environ. Res. 2018;16:1983-1997.

38. Logan BE, Hamelers B, Rozendal R, et al. Microbial Fuel Cells: Methodology and Technology. Environ. Sci. Technol. 2006;40: 5181-5192.

39. Wang M, Yan Z, Huang B, Zhao j, Liu R. Electricity generation by microbial fuel cells fuelled with enteromorpha prolifera hydrolysis. Int. J. Electrochem Sci. 2013;8:2104-2111.

40. Cheng S, Liu H, Logan BE. Increased performance of single-chamber microbial fuel cells using an improved cathode structure. Electrochem. Commun. 2006;8:489-494.

41. Sharma Y, Li B. Optimizing energy harvest in wastewater treatment by combining anaerobic hydrogen producing biofermentor (HPB) and microbial fuel cell (MFC). Int. J. Hydrog. Energ. 2010;35:3789-97.

42. Fan Y, Hu H, Liu H. Enhanced Coulombic efficiency and power density of air-cathode microbial fuel cells with an improved cell configuration. J. Power Sources. 2007;171:348-354.

43. Chae K-J, Choi M-J, Lee J-W, Kim K-Y, Kim IS. Effect of different substrates on the performance, bacterial diversity, and bacterial viability in microbial fuel cells. Bioresour. Technol. 2009;100: 3518-3525. 